\title{
Assessment of Nurses' Knowledge Regarding Breast Cancer at Primary Health Care Centers in Al-Sader District
}

Ammar A Okab (MSc) ${ }^{1}$

\section{Abstract}

Background: Breast cancer is the most common, prevalent and diagnosed that affects women and the leading cause of death and disability worldwide and is a leading cause of morbidity and mortality among women.

Objective: To assess the levels of knowledge among nurses regarding breast cancer at primary health care centers in Al-Sader district and to find out the relationship between socio- demographic characteristic and levels of knowledge.

Patients and Methods: A cross-sectional study in which assessment approach is applied to achieve objectives of study, The period of the study was from 2nd July 2017 to 28th May 2018. The sample was non-probability (purposive sample) of 50 nurses who working at primary health care centers in Al-Sader district and selected according to criteria of sample and for the purpose of the study. A questionnaire used was consist of (37) items which was distributed across (2) main parts which are the socio-demographic characteristics which included (7) items, to assess levels of knowledge regarding the breast cancer these comprised (30) items. Data analysis by using program of SPSS version 20. Descriptive data through determination of: frequencies, percentages and mean of score to measure the level of knowledge to nurses. Inferential statistical data analysis by application $\mathrm{Chi}$-square test used this for determine the association between the nurse's socio-demographic characteristics and knowledge of nurses about breast cancer.

Results: Results of the study that more than half of nurses with good levels of knowledge regarding breast cancer and there are significant association between sources of information and knowledge of nurses regarding breast cancer.

Conclusion: That establish specially heath educational programs that provide information about breast cancer to the community.

Keywords: Assessment, Nurses, Knowledge, Breast Cancer, Primary Health Care Centers Corresponding Author: amarabas4@gmail.com

Received: $19^{\text {th }}$ February 2019

Accepted: $5^{\text {th }}$ May 2019

\footnotetext{
${ }^{1}$ Technical Nursing Department-Technical Institute-Suwaira-Middle Technical University - Iraq
}

\section{Introduction}

Cancer is the leading cause of death health problem both in underdeveloped and worldwide and it is an important public developing countries. Globally, breast cancer 
is the most common cancer among women [1].

Breast cancer is the most common among women, prevalent and diagnosed that affects women and the leading cause of death and disability worldwide and is a leading cause of morbidity and mortality among women[2].The important reason of disease was diagnosed in progress stages, and multiple barriers to diagnosis and treatment for most women who depend on the public health care, a tumor with good prognosis in most cases and when diagnosed and treated in appropriate time, therefore breast cancer had correlating with high rate of mortality [3].

Risk of breast cancer that threat women who lived in Iraq for the last twenty years ago. Every year, 1000-1200 new cases are recorded. Breast cancer occupies $14 \%$ of the whole in different type of cancers and a rate of 1-6 of women are affected from every 100000 [4].First cause of breast cancer is unknown, another causes Including; genetic, hormone, environmental toxins, biological and physiological factors, $1 \%-2 \%$ yearly in developing countries the risk of developing breast cancer has increased [5].

Family history characteristics that suggest hereditary predisposition to breast cancer include, early age at diagnosis, multiple synchronic or met chronic primary tumors, male breast cancer and correlation with another tumors such as ovarian and prostate cancers [6]. The important resource of dissemination of breast cancer knowledge to women are the health-care professionals, educational institutions and media. Among the healthcare professionals, female nurses comprise the group most suited for this purpose [7].

Nurses have a major role in the multidisciplinary team involved in the care of patients with breast cancer, as well as those at increased risk for the disease. Therefore, it is essential to invest in the Knowledge, education and training of nurses, Knowledge and identification of risk factors for breast cancer are key challenges for health promotion and cancer prevention within nursing practice [8].

The nurses play an important role in educating women through special educational programs in the clinical setting, through community outreach strategies of our social and cultural setting. In addition, they constitute an important source of information [9].

\section{Patients and Methods}

A cross-sectional study in which assessment approach is applied to achieve objectives of study, The period of the study was from 2nd July 2017 to 28th September 2017. The sample was non-probability (purposive sample) of 50 nurses from (20) primary health care centers in Al-Sader sector and selected according to criteria of sample and for the purpose of the study.

A questionnaire is consist of [37] items which are distributed across 2 main parts which are the socio-demographic characteristics which included [7] items, and to assess levels of knowledge regarding breast cancer this comprised [30] items. 


\section{Statistical analysis}

Participant's responses were analyses by using program of (SPSS) version 20. Descriptive data through determination of: frequencies, percentages and mean of score to measure the level of knowledge to nurses. Inferential statistical data analysis by application Chi-square test used this for determine the association between the nurse's socio-demographic characteristics and knowledge of nurses about breast cancer (Based on Chi-squire : Sig. $\mathrm{P} \leq 0.05$ Highly Sig. At $\mathrm{P}<0.01$. And Non Sig.AtP $>0.05)(10)$.

\section{Results}

Table (1): Socio-demographic characteristics of nurses.

\begin{tabular}{|c|c|c|c|}
\hline \multicolumn{2}{|c|}{ Socio-demographic characteristics } & No. & $\%$ \\
\hline \multirow{5}{*}{ Age } & $20-30$ & 9 & $18 \%$ \\
\hline & $31-40$ & 13 & $26 \%$ \\
\hline & $41-50$ & 21 & $42 \%$ \\
\hline & Above 51 & 7 & $14 \%$ \\
\hline & Total & 50 & $100 \%$ \\
\hline \multirow{5}{*}{ Marital status } & Single & 22 & $44 \%$ \\
\hline & Married & 16 & $32 \%$ \\
\hline & Widowed & 3 & $6 \%$ \\
\hline & Divorce & 9 & $18 \%$ \\
\hline & Total & 50 & $100 \%$ \\
\hline \multirow{4}{*}{ Education level } & Nursing school & 8 & $16 \%$ \\
\hline & Preparatory nursing school & 22 & $44 \%$ \\
\hline & Institute and more & 20 & $40 \%$ \\
\hline & Total & 50 & $100 \%$ \\
\hline \multirow{4}{*}{ Economic status } & Enough & 12 & $24 \%$ \\
\hline & enough some times & 18 & $36 \%$ \\
\hline & not enough & 20 & $40 \%$ \\
\hline & Total & 50 & $100 \%$ \\
\hline \multirow{5}{*}{ Source of information } & Doctor & 17 & $34 \%$ \\
\hline & Nurses & 20 & $40 \%$ \\
\hline & Media & 10 & $20 \%$ \\
\hline & Another source & 3 & $6 \%$ \\
\hline & Total & 50 & $100 \%$ \\
\hline \multirow{5}{*}{ Time of health services } & from 1 years to 5 & 5 & $10 \%$ \\
\hline & $6-10$ & 7 & $14 \%$ \\
\hline & $11-15$ & 7 & $14 \%$ \\
\hline & more than 16 & 31 & $62 \%$ \\
\hline & Total & 50 & $100 \%$ \\
\hline \multirow{3}{*}{$\begin{array}{l}\text { Participated in training courses } \\
\text { about breast cancer }\end{array}$} & Yes & 20 & $40 \%$ \\
\hline & No & 30 & $60 \%$ \\
\hline & Total & 50 & $100 \%$ \\
\hline
\end{tabular}

No. $=$ Number, $\%=$ Percentage 
Results out of this table reveal the sociodemographic characteristic of (50) participated nurses; $(42 \%)$ from them were 41-50 years old, (44\%) were single, (44\%) were preparatory nursing school level of education, $(60 \%)$ of them say not enough for economic status, (40\%) were the major source of information about breast cancer from nurse, $(62 \%)$ of them the time of health services more than 16 years and $(60 \%)$ of nurses don't participated in training courses about breast cancer.

Table (2): The levels of nurses' knowledge regarding Breast Cancer.

\begin{tabular}{|c|c|c|c|}
\hline \multicolumn{4}{|c|}{ Knowledge } \\
\hline Level & M.S & No. & $\%$ \\
\hline Poor & $1-1.66$ & 12 & $24 \%$ \\
\hline Intermediate & $1.67-2.33$ & 11 & $22 \%$ \\
\hline Good & $2.34-3$ & 27 & $54 \%$ \\
\hline Total & $1-3$ & 50 & $100 \%$ \\
\hline
\end{tabular}

This table reveals more than half of level regarding breast cancer. participated nurses have good knowledge

Table (3): Association between Socio- demographic characteristics and nurses' knowledge.

\begin{tabular}{|c|c|c|c|c|}
\hline \multirow{2}{*}{ Demographic Characteristics } & \multirow{2}{*}{ No. } & \multirow{2}{*}{ Df } & \multicolumn{2}{|c|}{ Knowledge } \\
\hline & & & $P$-value & C.S \\
\hline Age & \multirow{7}{*}{50} & 2 & 0.45 & Non \\
\hline Marital status & & 3 & 0.19 & Non \\
\hline Education level & & 6 & 0.18 & Non \\
\hline Economic status & & 2 & 0.26 & Non \\
\hline Source of information & & 2 & 0.02 & $\mathrm{~S}$ \\
\hline Time of health services & & 2 & 0.32 & Non \\
\hline $\begin{array}{c}\text { Participated in training courses } \\
\text { about breast cancer }\end{array}$ & & 2 & 0.04 & $S$ \\
\hline
\end{tabular}

$\mathrm{Df}=$ degree of freedom, No. = Number, P: probability value, S: Significant at $\mathrm{P}<0.05$, NS: Non-significant at P $>0.05$, C.S : Comparative Significant

Results out of this table that significant association between sources of information and participated in training courses with knowledge of nurses about breast cancer .

\section{Discussion}

Socio-demographic characteristic of nurses:According to age, most of study participants (42\%) from them were 41-50 years old, (44\%) were single, A study presented supportive evidence to this result by Semarya B. et al (11) they studied age range of participants was from 21 to 58 years and as to the marital status $169(62.6 \%)$ were single and 87 (32.2\%) married. (44\%) were preparatory nursing school level of education, because the policy of Ministry of 
Health don't allow the academic nurse to work in primary health care. $(60 \%)$ of them say not enough for economic status, $(40 \%)$ were the major source of information about breast cancer from nurse, $(62 \%)$ of them the time of health services more than 16 years and $(60 \%)$ of nurses don't participated in training courses about breast cancer Table (1).

Discussion of the levels of nurses' knowledge regarding breast cancer:The results of this table revealed that more than half participated nurses have good knowledge level regarding breast cancer. Because the ministry of health provided support to continuing nursing education in all health institutions to present the information about breast cancer and another diseases. A study presented not supportive evidence to this result by Alkhasawneh IM (12) they studied Nurses have low mean levels of knowledge about early detection and facts related to breast cancer in Jordan ( $X=51 \%$, SD = 19), continuing nursing education program are very important to improve knowledge level of nurses regarding breast cancer Table (2).

Discussion of the Association between socio-demographic characteristic and nurses 'knowledge:The findings of the present study shows that statistical significant association between items which are related to the nurses' knowledge and sources of information regarding breast cancer. The sources of information regarding breast cancer play an important role to change and increase the awareness and knowledge about breast cancer and to recognize the risk factors who affected. While shows that no statistical significant association between items which are related to (age, marital status, education level, economic status and time of health services) and nurses' knowledge Table(3).

Also shows statistical significant association between of the items which is related to the nurses' knowledge and participated in training courses about breast cancer. The training courses increase the knowledge and practice to educated about breast cancer, and who learn the another female in work place and community to deal with this disease.

\section{Conclusions}

The present study concluded that nearly half age of nurses (42\%) from (41-50) years old, (44\%) from them were preparatory nursing school level of education, major source of information regarding breast cancer from nurse $(40 \%)$, there are good knowledge of nurses regarding breast cancer, there's significant association between knowledge and sources of information and significant association between participated in training courses breast cancer and knowledge of nurses regarding breast cancer.

\section{Recommendations}

According to the results of study the recommendations that:

1-Establish specially heath educational programs that provide information regarding breast cancer to the community.

2-Encourage the study about risk factors related breast cancer in Iraq. 
3-Nurses need to promote their knowledge regarding breast cancer by continuing nurses education programs.

\section{References}

[1]Jemal A, Siegel R, Xu J, Ward E. Cancer statistics, 2010. CA Cancer J Clin. 2010;60(5):277-300.

[2]Jemal A, Bray F, Center MM, Ferlay J, Ward E, Forman D. Global cancer statistics. CA Cancer J Clin 2011.

[3]Carmen Maria Dornelles Prolla, Patrícia Santos da Silva, Cristina Brinckmann Oliveira Netto, José Roberto Goldim, and Patricia Ashton-Prolla, Knowledge about breast cancer and hereditary breast cancer among nurses in a public hospital, Revista Latino-Americana de Enfermagem. 2015 Jan-Feb; 23(1): 90-97.

[4] Agarwal, G.; Pradeep, P.; Aggarwal, V.; Yip, C. and Cheung, P.: Spectrum of Breast Cancer in Asian Women. Department of Endocrine and Breast Surgery, Sanjay Gandhi Postgraduate Institute of Medical Sciences, Raebareli Road. World J Surg. 2007.

[5]Oussama M.N. Khatib and Atord Modjtabai , Guidelines for the early detection and screening of breast cancer , World Health Organization, 2006.

[6]MacDonald DJ. Germline Mutations in Cancer Susceptibility Genes: An Overview for Nurses Seminars in Oncology Nursing. 2011.

[7]Faiza Ahmed, Sadia Mahmud, Juanita Hatcher, Shaista M Khan , Breast cancer risk factor knowledge among nurses in teaching hospitals of Karachi, Pakistan: a cross- sectional study, BMC Nursing , 2006 Sep, vol 5 (6).

[8]Carmen Maria, D Prolla, , Patrícia Santos, Cristina, Netto, and J Goldim, Knowledge about breast cancer and hereditary breast cancer among nurses in a public hospital , brazil , 2015.

[9]F. Ahmed, S. Mahmud, J. Hatcher and S. $\mathrm{M}$ Khan, Breast cancer risk factor knowledge among nurses in teaching hospitals of Karachi, Pakistan: BMC Nursing 2006 , can be found online at: http://www.biomedcentral.com/14726955/5/6.

[10]Polit, D. hungler, B.: Principles and Method, Nursing Research, 6(1), 2012, pp. 418.

[11] Semarya B, Worknish S, Mignote H, Mesfin A, and Alemseged A. , Assessment of Knowledge of Breast Cancer and Screening Methods among Nurses in University Hospitals in Addis Ababa, Ethiopia, 2011.

[12]Alkhasawneh IM., Knowledge and practice of breast cancer screening among Jordanian nurses, 34(6), 2007. 